\title{
Methodes of Power Quality Analysis
}

\author{
Gabriel Găşpăresc \\ "Politehnica" University of Timişoara \\ Romania
}

\section{Introduction}

In the last decades electronics and telecommunications have known an unprecedented development, the number of non-linear loads (power electronics) has increased. New more energy efficient devices and equipments, controlled by microprocessors, have appeared. They are also more sensitive to electromagnetic disturbances, produced by neighborhood devices or as a result of the shared infrastructure, which can affect the power quality for many industries or even for the domestic consumers. A poor power quality can cause the malfunction of electrical and electronic devices and equipments, instability, short lifetime. In case of computers the disturbances may lead to: corrupted files, losing files and to the destruction of the hardware components. Additional costs can occur for both, suppliers and consumers (for instance, after a power interruption on a production line a certain time is needed to restart, which leads to a reduction in production) (Bollen et al., 2006), (Dungan et al., 2004), (Ignea, 1998).

Simultaneously, the expansion of the suppliers, the competition on the market, the increase of the studies in this field, the better informed customers have led nowadays to higher requirements for power quality. Both categories, the suppliers and the consumers are more concerned about the power quality. In order to satisfy consumers' requirements, suppliers have invested in more energy efficient equipments. Frequently, just these are affected by power problems, and they become in turn disturbances sources.

A power quality monitoring system provides huge volume of raw data from different locations, acquired during long periods of time and the amount of data is increasing daily (Barrera Nunez et al., 2008). The visual inspection method is laborious, time consuming and is not a solution. Features extraction of power quality disturbances using methods of power quality analysis, in order to achive automatic disturbance recognition, is important for understanding the cause-effect relation and to improve the power quality.

Features extraction of power quality disturbances using methodes of power quality analysis, in order to achive automatic disturbance recognition, is important for understanding the cause-effect relation and to improve the power quality.

The classical method of power quality analysis used in power quality monitoring sytems has been the discrete Fourier transform (DFT). Nowadays new methods has been proposed in literature: short time Fourier transform (STFT) (Bollen et al., 2006), discrete wavelet transform (DWT) (Driesen et al., 2003) and discrete Stockwell transform (DST) (Gargoom, 2008). Sometimes those methodes are integrated in company with fuzzy logic (FL) (Chilukuri et al., 2004), artificial neural networks (ANN) (Dash, 2007), (Gang, 2004) or super vector machines (SVM) (Yong, 2005). A comparative study is presented as follows. 


\section{Discrete Fourier transform}

In Fourier analysis a signal is decomposed into a sum of sinusoidal signals (harmonics). The Fourier transform is a mathematical transformation from the time domain to the frequency domain.

The Discrete Fourier Transform (DFT) provides frequency domain analysis of discrete periodic signals. For such a signal $x[n]$ with finite length $N$ the Fourier transform is defined according to next relation

$$
X(k)=\sum_{n=0}^{N-1} x[n] e^{-j \frac{2 \pi}{N} k n}
$$

where $k=0,1, \ldots, N-1$.

For the input signal $x[n]$ if the number of samples $N$ is power of 2 it can be applied FFT (Fast Fourier Transform) algorithm. The aim of the algorithm is to reduce the number of operations and implicit the calculation time.

The use of Fourier transform for signals affected by electromagnetic disturbances reveals changes of spectral components of initial signals caused by the disturbances presence. Fig. 1 shows a sinusoidal signal disturbed with harmonic distortions. From the frequency spectrum, obtained appling FFT on this signal, are calculated the odd harmonic orders: the 3 rd, 5th and 7 th.
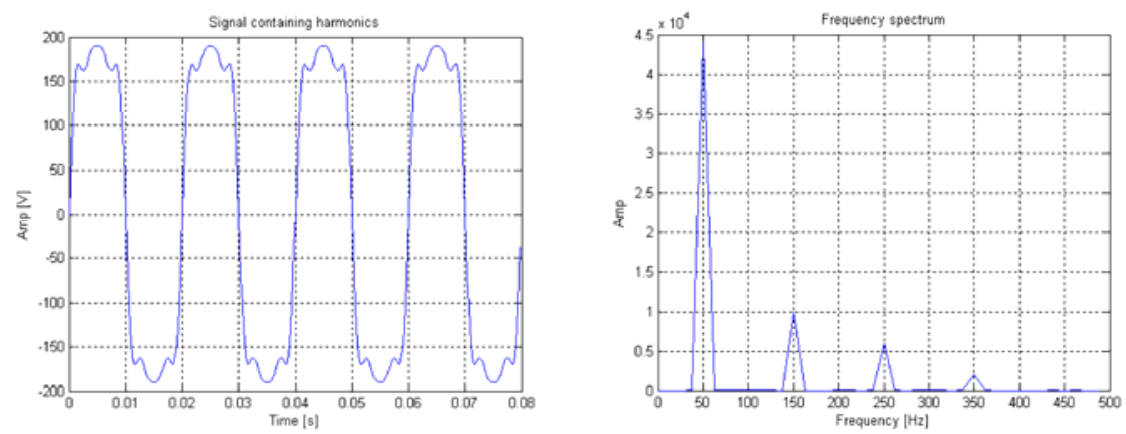

Fig. 1. Harmonic distortions
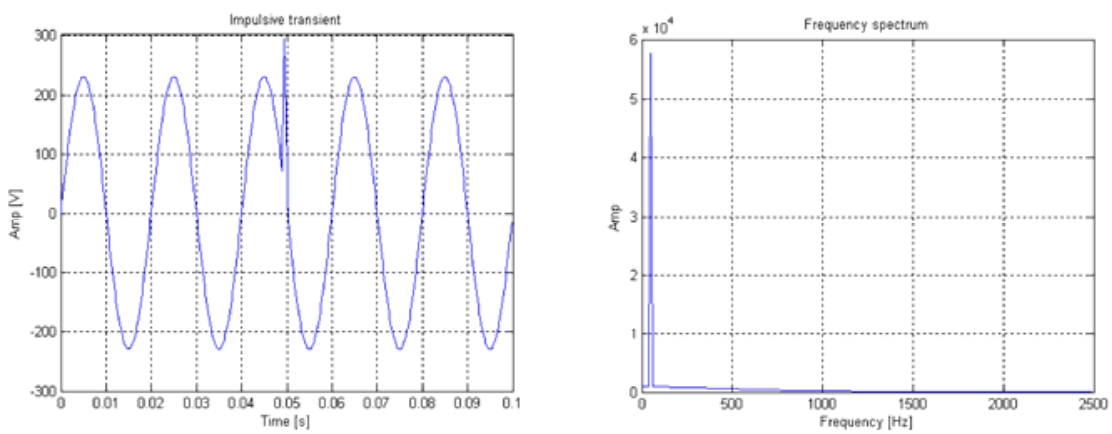

Fig. 2. Impulsive transient 
In most cases the power quality disturbances are nonstationary and nonperiodic. For power quality analysis is useful to achive time localization of the disturbances (determining the start and end times of the event) which can not be done by Fourier transform. The limitation is obvious especially for transient phenomenas (quick variations), difficult to observe visually. In Fig. 2 is considered a sinusoidal signal disturbed with an impulsive transient. Like in Fig. 1 below, the frequency spectrum provides informations about frequency spectral components but no information about time localization.

\section{Short time Fourier transform}

The Short-Time Fourier Transform (STFT) provides informations in time domain (start time, stop time, rise time, duration) and frequency domain about disturbances. Usually signals parameters (amplitude, frequency, phase) are not constants in time and the signals are nonstationary. For a discrete signal $x[n]$ the discrete transform is defined

$$
X[n, \lambda]=\sum_{m=-\infty}^{\infty} x[n+m] w[m] e^{-j \lambda m}
$$

where $w[m]$ is a window function with size $L$.

Usually the number of samples $N$ of the signal $x[n]$ is finite and the window $w[m]$ has the next expression

$$
\begin{aligned}
& w[l] \neq 0, \text { for } 0 \leq l \leq L-1 \\
& w[l]=0, \text { for } l<0 \text { and } l \geq L
\end{aligned}
$$

where $L$ is window size.

The window size $L$ can be smaller or equal to $N$, the number of samples of signal $x$ [ $]$

$$
N \geq L
$$

Relation (2) becomes

$$
X[n, \lambda]=\sum_{l=0}^{L-1} x[n+l] w[l] e^{-\frac{j l \lambda}{N}}
$$

The square modulus of short time Fourier transform is called spectrogram and is a time-frequency representation.

Power quality disturbances cover a broad frequency spectrum, starting from a few $\mathrm{Hz}$ (flicker) to a few $\mathrm{MHz}$ (transient phenomenas). The frequency spectrum of a signal affected by a transient voltage contains high frequency components and also low frequency components. It is difficult to analyze such a signal using the STFT because the window size and implicit time-frequency resolution are fixed.

\subsection{Window functions}

The window functions are useful for time domain smoothing of acquired signals, reduction of spectral distortions and better resolution.

Main parameters of window function are:

- main lobe width; 
- $\quad$ side lobe attenuation;

- minimum stopband attenuation.

The main lobe width has influence on frequency resolution. The possibility to distinguish two signals with close frequencies increases when the lobe width decreases, but for a narrow lobe the energy of side lobes increase against main lobe energy. The results are the increase of side lobe amplitudes and attenuation. Consequently, it is necessary a compromise between time and frequency resolution. A narrow window provides a good time resolution while a large one is useful for good frequency resolution.

Figure 3 shows the time domain and frequency domain representations of the rectangular, Hanning and Hamming window.
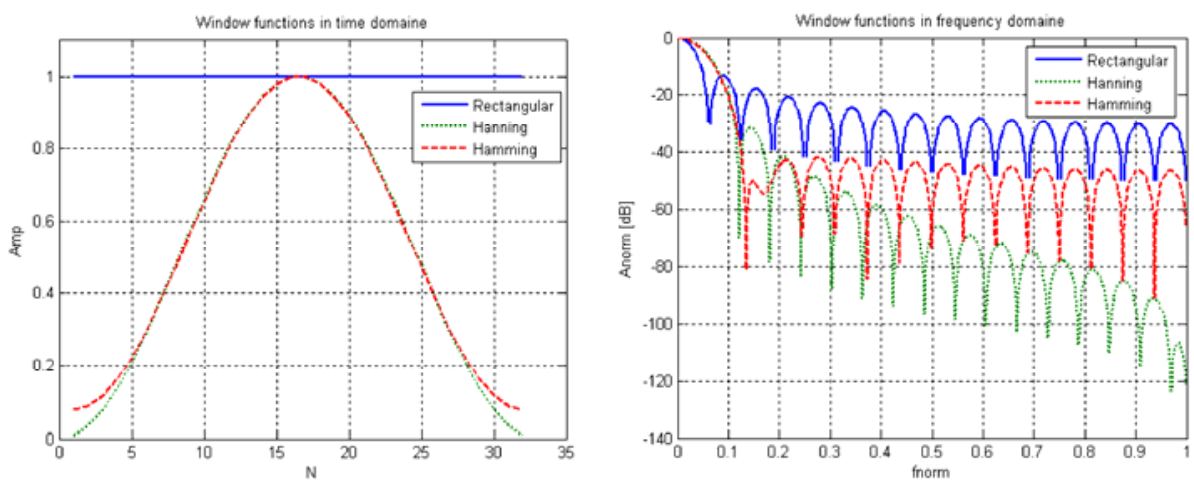

Fig. 3. Window functions

The rectangular window is defined in the next relation

$$
w(n)=1
$$

where $n=0,1,2, N-1$ and $N$ is window size.

This function (fig. 3) provides just time truncation of signals, it does not affect the amplitudes of signals and the spectral distortions are the biggest from window functions. It is useful in analysis of transient disturbances with duration smaller like window size and close amplitudes.

The Hanning window is defined as

$$
w(n)=0,5+0,5 \cos \left(\frac{2 n \pi}{N}\right)
$$

where $\mathrm{n}=0,1,2, \mathrm{~N}-1$.

The window has lower side lobes like previous function (fig. 3). It is used for transient disturbances with duration bigger like window size, usually when the signals components are not knowed The Hamming window is described in next relation

$$
w(n)=0,54+0,46 \cos \left(\frac{2 n \pi}{N}\right)
$$


where $\mathrm{n}=0,1,2, \mathrm{~N}-1$.

In time domain the window has a shape similar to the Hanning window (fig. 3), the differences are: the ends of window are not so close to zero, in frequency domain the side lobes are lower and main lobe width is larger. It is used specially for sinusoidal signals with close frequencies.

The table 1 shows the side lobe level of smoothing windows: the rectangular window has the lowest attenuation level and the Hamming window has the highest value.

\begin{tabular}{|c|c|}
\hline Window function & Side lobe level [dB] \\
\hline Rectangular & -13 \\
\hline Hanning & -31 \\
\hline Hamming & -42 \\
\hline
\end{tabular}

Table 1. Side lobe level of smoothing windows

\subsection{Using the STFT-transform for transient signal analysis}

A sinusoidal signal with frequency of $50 \mathrm{~Hz}$ is disturbed by an oscillatory transient with the frequency of $1000 \mathrm{~Hz}$. The obtained spectograms for rectangular, Hanning and Hamming windows, with size 16, are presented in figure 4.
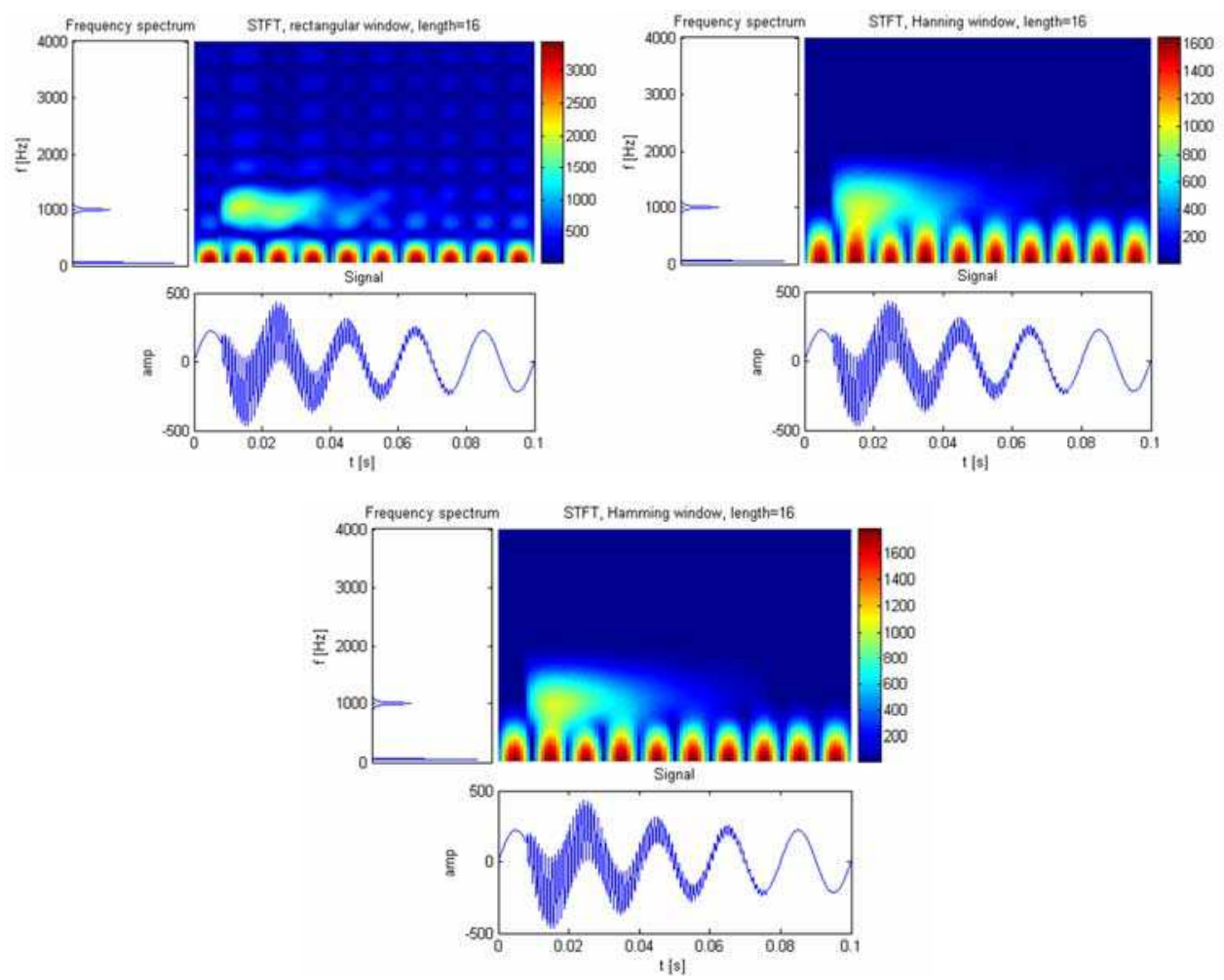

Fig. 4. STFT of an oscillatory transient 
From previous figure it can be seen that for rectangular window the spectral distorsions are the biggest, it fallows Hanning window with smaller distortsions and Haming window with the smallest distortsions (according to Table 1). Suplementary, for the disturbance it can be observed the start time, stop time, duration and frequency domain.

The influence of window size is shown in figure 5. The increase of window size it has increased also the resolution in frequency domain, but has decreased the resolution in time domain. In figure 5, for the window with the largest width, it can be seen that the maximum spectral component is $1000 \mathrm{~Hz}$ and this value is the frequency of oscillatory transient overlapped on the sinusoidal signal. In the time domain appears a sliding to zero in comparison with the rest of spectrograms.
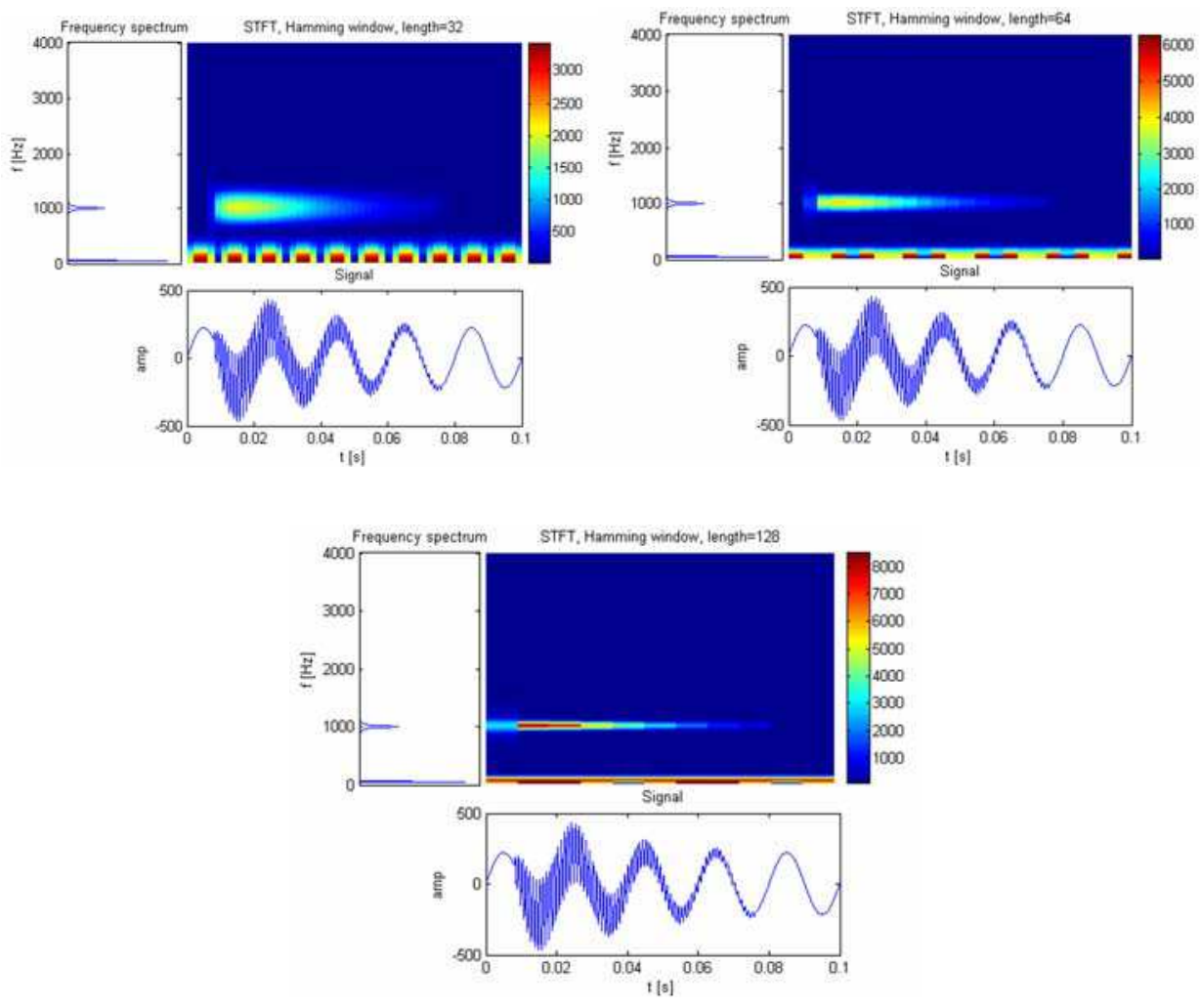

Fig. 5. Influence of window size on time and frequency resolution

A solution to obtain high resolution in the time domain and also in the frequency domain is to use two window functions with different size: a narrow window for good time resolution and a large window for good frequency resolution. Than the STFT is applied two times using both windows. But this method has a disadvantage, it increases the number of operations.

Figure 6 shows the spectograms obtained for a sinusoidal signal with frequency of $50 \mathrm{~Hz}$ disturbed by an oscillatory transient with the frequency of $1500 \mathrm{~Hz}$ (the sampling rate is 
$8000 \mathrm{~Hz}$ ). The first spectogram is obtained using a narrow window (16 samples) and is useful for time localization. For the second spectrogram is used a large window (480 samples). In this case it can be seen the frequency of the oscillatory transient.
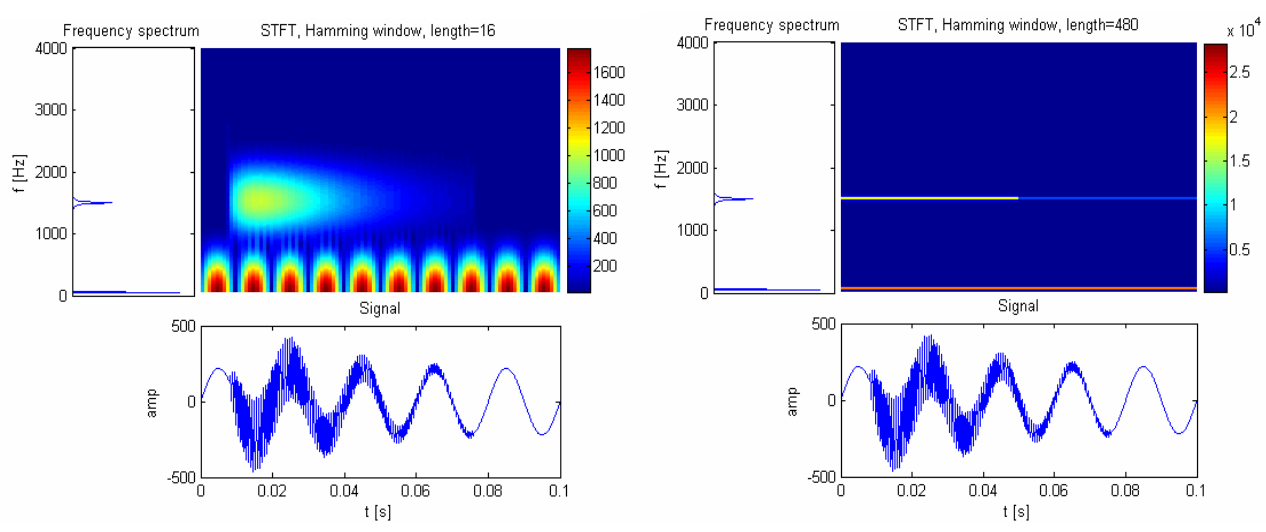

Fig. 6. Using STFT with two window functions

\section{Discrete wavelet transform}

The wavelet transform is an alternative solution in order to overcome the limitations of STFT. Multiresolutions signal decompositon is based on subbads decomposition using low-pass filtering and high-pass filtering. This transform ensure progressive resolution for time localization and characterization of the transient phenomenas.

The Fourier analysis decomposes a signal into a sum of harmonics and wavelet analysis into wavelets. A wavelet is a waveform of limited duration, usually irregular and asymmetric. For a discrete signal $x[n]$ the discrete transform is defined

$$
x(t)=A_{j 0}(t)+\sum_{j=0}^{j 0} D_{j}(t)
$$

where

$$
\begin{aligned}
& A_{j}(t)=\sum_{k} c_{j}(k) \varphi_{j, k}(t) \\
& D_{j}(t)=\sum_{k} d_{j}(k) \Psi_{j, k}(t)
\end{aligned}
$$

$c_{j}(k)$ are the scaling function coefficients and $d_{j}(k)$ are the wavelet function coefficients, $j_{0}$ is the scale and $\varphi(t)$ is the scaling function.

For a given signal $x(t)$ and a three level wavelet decomposition the relation (9) become

$$
x(t)=A_{1}+D_{1}=A_{2}+D_{2}+D_{1}=A_{3}+D_{3}+D_{2}+D_{1}
$$

and at each decomposition level the signal is split into an approximation and a detail. 
In order to classify the disturbances using disturbances patterns is necessary to calculate the deviation between the energy distributions of the disturbed signal and the clean signal (Vega, 2009), (Resende, 2001)

$$
d p(j)[\%]=\left[\frac{e n \_d i s t(j)-e n \_r e f(j)}{e n \_r e f(m)}\right] * 100
$$

where

$j$ is the wavelet transform level;

$d p(j)[\%]$ is the deviation between the energy distributions;

en_dist $(j)$ is the energy distribution of the disturbed signal;

en_ref(j) is the energy distribution of the clean signal (or fundamental component of the disturbed signal).
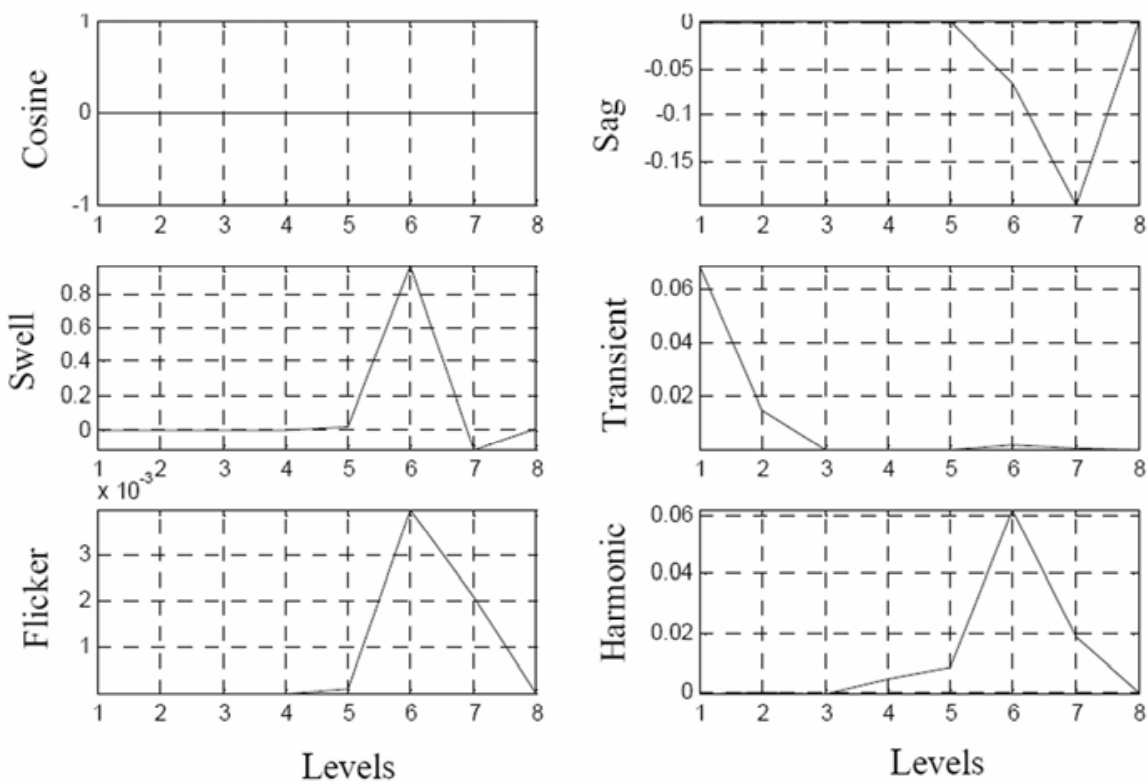

Fig. 7. Disturbances patterns

The energy distributions are calculated based on Parseval's theorem: "the energy that a time domaine function contains is equal to the sum of all energy concentrated in in the different resolution levels of the corresponding wavelet transformed signal" (Resende, 2001). According to this theorem we have (Gaouda, 1999)

$$
\sum_{n=1}^{N}|f(n)|^{2}=\sum_{n=1}^{N}\left|a_{J}\right|^{2}+\sum_{j=1}^{J} \sum_{n=1}^{N}\left|d_{j}(n)\right|^{2}
$$

where

$f(n)$ is the time domaine signal; 
$N$ is the number of signal samples; the total energy of the $f(n)$ signal is

$$
\sum_{n=1}^{N}|f(n)|^{2}
$$

the total energy concentrated in the level $j$ of the approximation coefficient is

$$
\sum_{n=1}^{N}\left|a_{J}\right|^{2}
$$

the total energy concentrated in the detail coefficients (from level 1 to level $j$ ) is

$$
\sum_{j=1}^{J} \sum_{n=1}^{N}\left|d_{j}(n)\right|^{2} .
$$

In figure 7 (Duarte, 2006) are shown the disturbances patterns for the main types of power quality disturbances.

\subsection{Using the discrete wavelet transform for transient signal analysis}

A sinusoidal signal with frequency of $50 \mathrm{~Hz}$ is disturbed by an oscillatory transient with the frequency of $1000 \mathrm{~Hz}$. The Daubechis "db10" function is used as mother wavelet (figure 8) and the signal is decomposed using 8 decomposition levels (figure 9). It can be seen that the coefficients $D_{2}$ and $D_{3}$ (Fig. 9) provide information on time localization of the oscillatory transient (start time, stop time, duration), magnitude and frequency spectrum.

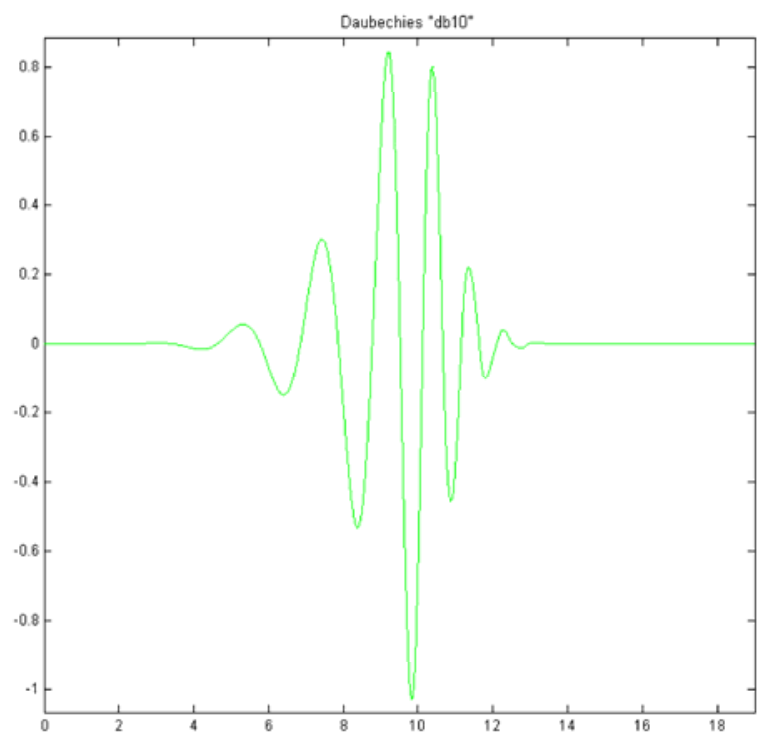

Fig. 8. The Daubechis "db10" function 

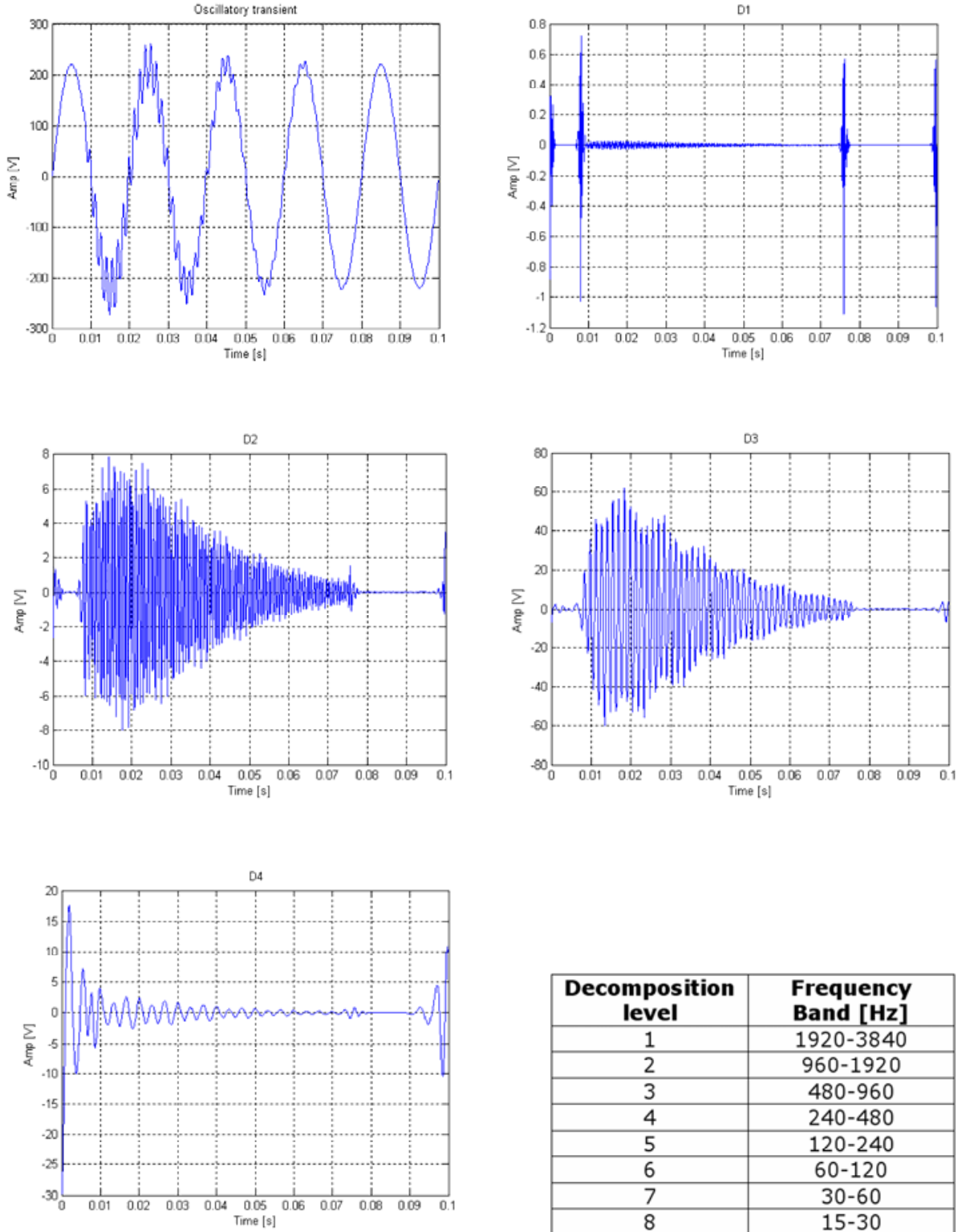

\begin{tabular}{|c|c|}
\hline $\begin{array}{c}\text { Decomposition } \\
\text { level }\end{array}$ & $\begin{array}{c}\text { Frequency } \\
\text { Band [Hz] }\end{array}$ \\
\hline 1 & $1920-3840$ \\
\hline 2 & $960-1920$ \\
\hline 3 & $480-960$ \\
\hline 4 & $240-480$ \\
\hline 5 & $120-240$ \\
\hline 6 & $60-120$ \\
\hline 7 & $30-60$ \\
\hline 8 & $15-30$ \\
\hline
\end{tabular}

Fig. 9. Eight-level discrete wavelet decomposition

Figure 10 shows that the energy is concentrated in the frequency bands of decomposition levels two and three $(240-960 \mathrm{~Hz})$ and the event is classified as low-frequency transient (Resende, 2001). 

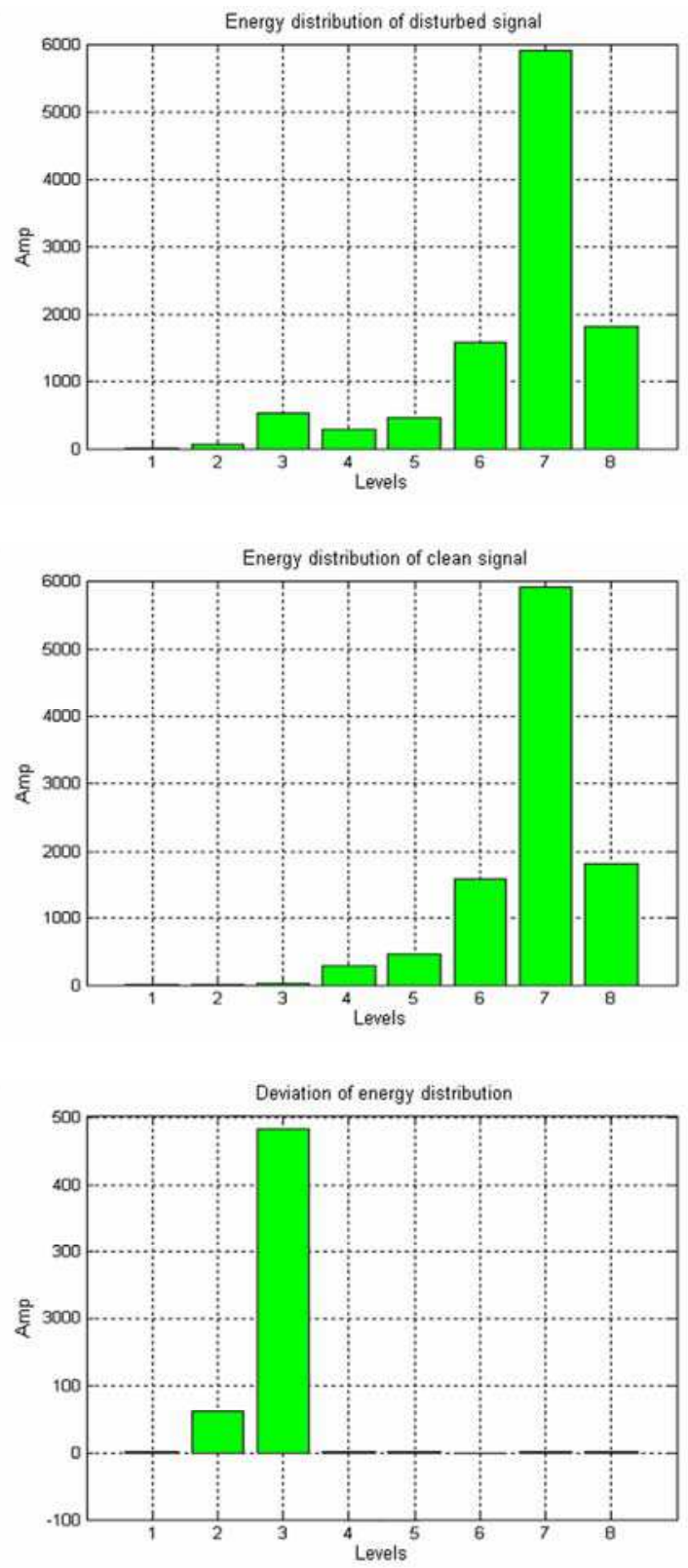

Fig. 10. Energy distribution

\section{Discrete Stockwell transform}

The discrete Stockwell transform (DST) of the $N$ point time series $h[k T]$ is 


$$
S\left[j T, \frac{n}{N T}\right]=\sum_{m=0}^{N-1} H\left[\frac{m+n}{N T}\right] e^{-2 \pi^{2} m^{2} / n^{2}} e^{i 2 \pi m j / N}
$$

where $n \neq 0$ and $H[n / N T]$ is the Fourier transform of time series.

The STFT transform limitation is the fixed window width, chosen a priori, for analysis of nonstationary signals containing low-frequency and high-frequency components. Consequently, the frequency-time resolution is fixed too and is difficult to analyze a sinusoidal signal of low frequecy (for instance the signal from power supply network) affected by a high frequency disturbance (for instance a transient phenomenon).

The wavelet transform limitations are: low resolution for low-frequency components, the decomposition frequency bands are fixed, noise sensitivity.

The $S$ transform is an extension of the wavelet transform resulted using a phase correction which provides superior resolution.

Applying DST on a signal the result is a matrix within the rows are frequences and the columns are time values.

\subsection{Using the S-transform}

To ilustrate the ability of the ST to detect, localize and quantify power quality disturbances are considered two signals. First signal is afected by a voltage swell (low-frequency components) and the second by an impulsive transient (high-frequency components). Figure 11 shows the 3D ST plots for both signals. From the 3D plots can be observed the amplitude variations of the frequency spectral components in the signals.

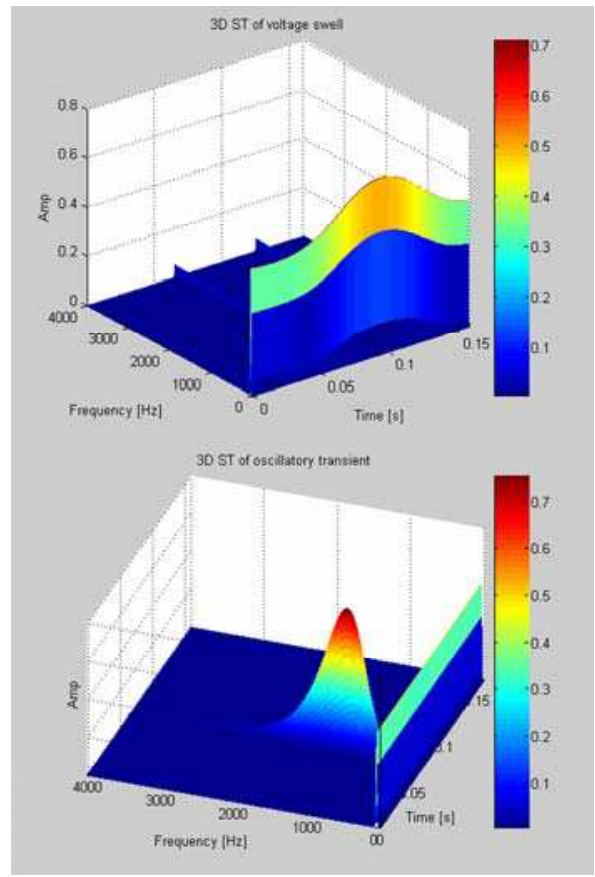

Fig. 11. S-transform 3D representation 
Figure 12 presents the ST of a clean signal and six types of power quality disturbances (voltage sag, voltage swell, voltage interruption, voltage harmonics, impulsive transient and oscillatory transient): a) the signal, b) the normalized time-frequency contour of ST, c) the maximum of amplitude-time characteristic of $S$ transform and $d$ ) the maximum of amplitude-frequency characteristic of of $S$ transform. From visual inspection of these plots are obtained amplitude, frequency and time information in order to detect, localize and classify the disturbance.
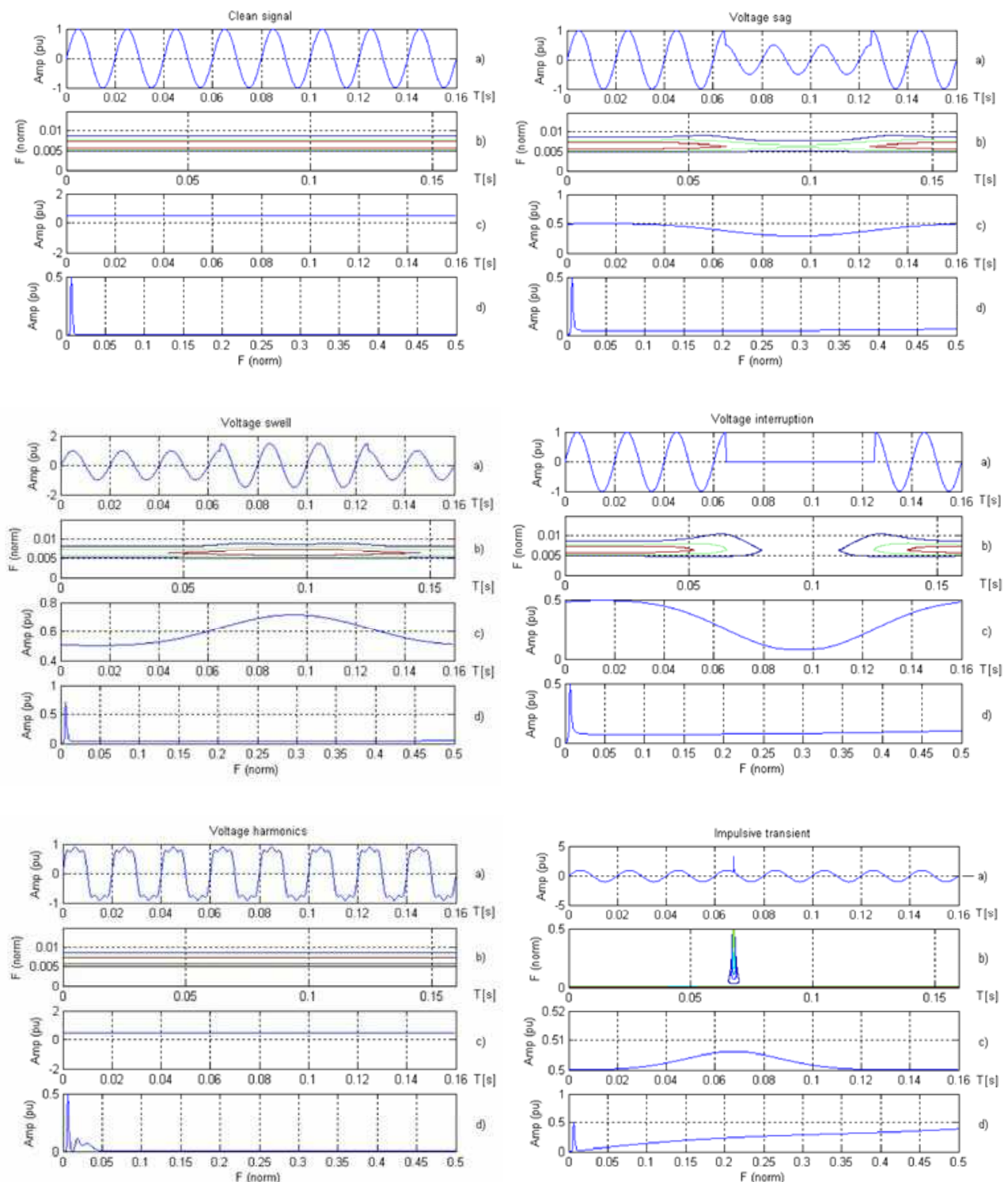


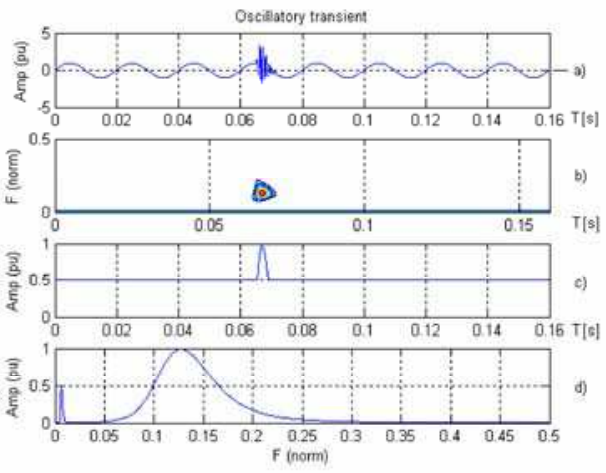

Fig. 12. S-transform

Figure 12 shows that the maximum of amplitude-time characteristic of $S$ transform is constant for the clean signal and voltage harmonics and the maximum of amplitudefrequency characteristic of $S$ transform reflects the changes in frequency domain due the presence of disturbances.

\section{Impulsive transient characterization}

The power quality disturbances that may occur in power supply networks are classified in various categories (Dungan, 2004): transient phenomenons, short duration variations, long duration variations, voltage imbalances, waveform distortions, power frequency variations and flickers.

Transient phenomenons are sudden and short-duration change in the steady-state condition of the voltage, current or both. These phenomenons are classified in two categories: impulsive and oscillatory transient. The first category has exponential rise and falling fronts and is characterized by magnitude, rise time (the time required for a signal to rise from $10 \%$ to $90 \%$ of final value), decay time (the time until a signal is greater than $1 / 2$ from its magnitude) and its spectral content.

In order to calculate the rise time for an impulsive transient (biexponential impulse) is proposed a simple algorithm. First are calculated $10 \%, 90 \%$ and $50 \%$ of peak amplitude. Than is necessary a loop to find the sample position of the previous values in waveform. Finally the rise time and the decay time are calculated as the difference between the positions found below. In Fig. 13 Rise time $c$ is calculated using the previously described method and Rise time is the exact value of rise time. In Fig. 14 Decay time $c$ is calculated also using the previous algorithm and Decay time is the exact value of decay time.

The result of the rise time calculation depends on sampling frequency. Table 2 contains the informations corresponding to a biexponential impulse (Fig. 13) when the sampling frequency is increased six times: $V e$ represents the exact value of rise time, $V 1$ and $V 2$ are the values obtained at low sampling rate and respectively at increased sampling rate, Er1 and $E r 2$ are the errors between $V 1$ and $V 2$ and respectively $V e$ and Er1/Er2 is the last column of Table 2. 

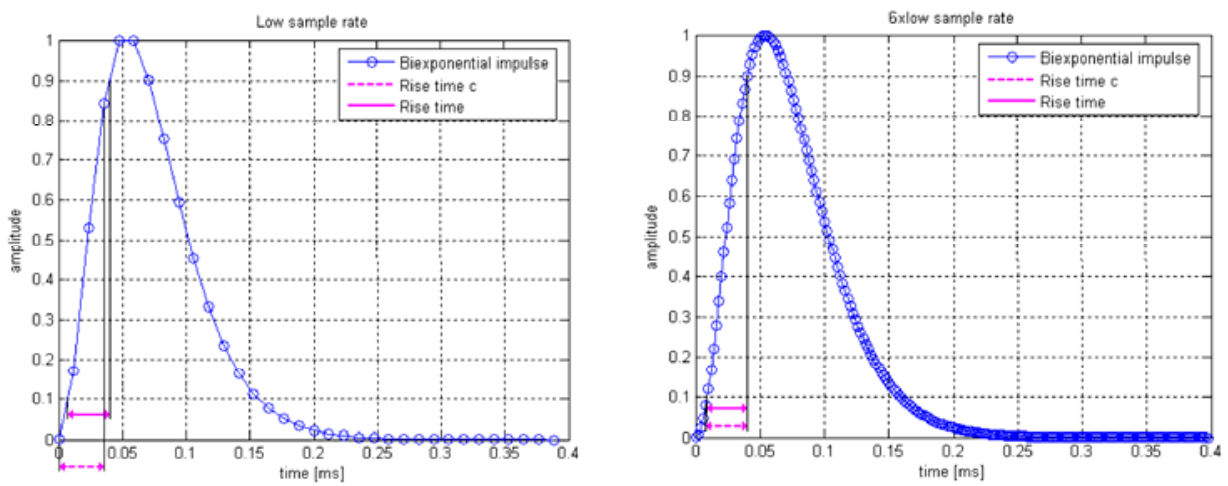

Fig. 13. Influence of sample rate on accuracy of rise time calculation

\begin{tabular}{|c|c|c|c|c|c|c|}
\hline & Ve & V1 & V2 & Er1 [\%] & Er2 [\%] & Er1/Er2 \\
\hline Tcr [ms] & 31.03 & 35.3 & 32 & 13.761 & 3.13 & 4.396 \\
\hline
\end{tabular}

Table 2. Rise time calculation

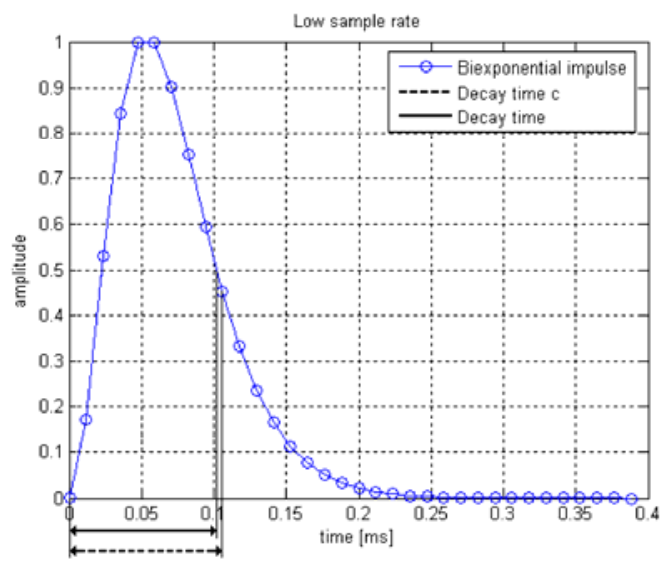

Fig. 14. Influence of sample rate on accuracy of decay time calculation

\section{Conclusion}

Nowadays, the researchers must to choose the most appropiate method to analyse the raw data. The main objectiv is features extraction of power quality disturbances in order to achive automatic disturbance recognition. A comparative study between DFT, STFT, DWT and ST is presented accompany with applications in power quality disturbances detection. Supplementary, a solution to improve the STFT analysis is described. Impulsive transients characterization is also presented. 


\section{References}

Amaris, H. ; Alvarez, C. ; Alonso, M. ; Florez, D. ; Lobos, T. ; Janik, P.; Rezmer, J. ; Waclawek, Z. (2009). Computation of Voltage Sag Initiation with Fourier based Algorithm, Kalman Filter and Wavelets, Proceedings of IEEE Bucharest PowerTech.

Azam, M. S.; Tu, F.; Pattipati, K. R.; Karanam, R. (2004). A Dependency Model Based Approach for Identifying and Evaluating Power Quality Problems, IEEE Transactions on Power Delivery 19(3) , pp. 1154-1166.

Barrera Nunez, V. ; Melendez Frigola, J. ; Herraiz Jaramillo, S. (2008). A Survey on Voltage Dip Events in Power Systems, Proceedings of the Internatiional Conference on Renewable Energies and Power Quality.

Bollen, M. H. J.; Gu, I. Y. H. (2006). Signal Processing of Power Quality Disturbances, John Wiley \& Sons.

Castro, R.; Diaz, H. (2002). An Overview of Wavelet Transform Application in Power Systems, Proceedings of the 14th Power Systems Computation Conference.

Chen, S.; Zhu, Y. (2007). Wavelet Transform for Processing Power Quality Disturbances, EURASIP Journal on Advances in Signal Processing.

Chilukuri, M. V.; Dash, P. K. (2004). Multiresolution S-Transform-based fuzzy recognition system for power quality events, IEEE Transaction on Power Delivery 19(1), pp. 323330.

Cornforth, D. ; Middleton, R. ; Tusek, J. (2000). Visualisation of Electrical Transients using the Wavelet Transform, Proceedings of the Internatiional Conference on Advances in Intelligent Systems.

Dash, P. K.; Nayak, M ; Senapati, M. R.; Lee, I. W. C.. (2007). Mining for similarities in time series data using wavelet-based feature vectors and neural networks, Engineering Applications of Artificial Intelligence 20, pp. 185-201.

Dehghani, M. D. (2009). Comparison of S-transform and Wavelet Transform in Power Quality Analysis, World Academy of Science, Engineering and Technology 50, pp. 395398.

Driesen, J. ; Belmans, R. (2002). Time-Frequency Analysis in Power Measurement using Complex Wavelets, Proceedings of the IEEE International Symposium on Circuits and Systems.

Driesen, J.; Belmans, R. (2003). Wavelet-based Power Quantification Approaches, IEEE Transactions on Instrumentation and Measurement 52(4), pp. 1232-1238.

Duarte, G., Cesar; Vega, G., Valdomiro; Ordonez, P., Gabriel (2006). Automatic Power Quality Disturbances Detection and Classification Based on Discrete Wavelet Transform and Artificial Intelligence, Proceedings of the IEEE PES Transmission and Distribution Conference and Exposition Latin America.

Dungan, R. C.; McGranaghan M. F., Santoso S., Beaty H. W. (2004). Electrical Power System Quality, McGraw-Hill.

Eldin, E. S. M. T. (2006). Characterisation of power quality disturbances based on wavelet transforms, International Journal of Energy Technology and Policy 4(1-2), pp. 74-84.

Fernandez, R. M. C.; Rojas, H. N. D. (2002). An overview of wavelet transforms application in power systems, Proceedings of the $14^{\text {th }}$ Power System Computational Conference.

Gang, Z. L. (2004). Wavelet-based neural network for power disturbance recognition and classification, IEEE Transaction on Power Delivery 19(4), pp. 1560-1568. 
Gaouda, A. M. ; Sultan, M. R. ; Chikhani, A. Y. (1999). Power Quality Detection and Classification Using Wavelet-Multiresolution Signal Decomposition, IEEE Transaction on Power Delivery 14(4), pp. 1469-1476.

Gargoom, A. M.; Ertugrul, N., Soong, W. L. (2008). Automatic Classification and Characterization of Power Quality Events, IEEE Transactions on Power Delivery 23(4), pp. 2417-2425.

He, H. ; Shen, X., Starzyk, J. A. (2009). Power quality disturbances analysis based on EDMRA method, International Journal of Electrical Power and Energy Systems 31, pp. 258-268.

Ignea, A. (1998). Introducere în compatibilitatea electromagnetică, Editura de Vest

Jena, G. ; Baliarsingh , R. ; Prasad, G. M. V. (2006). Application of S Transform in Digital Signal/Image, Proceedings of the National Conference on Emerging Trends in Electronics $\mathcal{E}$ Communication.

Khan, U. N. (2009). Signal Processing Techniques used in Power Quality Monitoring, Proceedings of the International Conference on Environment and Electrical Engineering.

Leonowicz, Z. ; Lobos, T. ; Wozniak, K. (2009). Analysis of non-stationary electric signals using the S-transform, The International Journal for Computation and Mathematics in Electrical and Electronic Engineering 28(2), pp. 204-2010.

Nath, S. ; Dey, A. ; Chakrabarti, A. (2009). Detection of Power Quality Disturbances using Wavelet Transform, Journal of World Academy of Science, Engineering and Technology 49 , pp. 869-873.

Panigrahi, B. K. ; Hota, P. K. ; Dash, S. (2004). Power Quality Analysis Using Phase Correlated Wavelet Transform, Iranian Journal of Electrical and Computer Engineering 3(2), pp. 151-155.

Reddy, J. B. ; Mohanta, D. K. ; Karan, B. M. (2004). Power System Disturbance Recognition Using Wavelet and S-Transform Techniques, International Journal of Emerging Electric Power Systems 1(2).

Resende, J. W. ; Chaves, M. L. R. ; Penna, C. (2001). Identification of power disturbances using the MATLAB wavelet transform toolbox, Proceedings of the International Conference on Power Systems Transients.

Samantaray, S. R. ; Dash, P. K. ; Panda, G. (2006). Power System Events Classification Using Pattern Recognition Approach, International Journal of Emerging Electric Power Systems 6(1).

Saxena, D. ; Verma, K. S. ; Singh, S. N. (2010). Power quality event classification: an overview and key issues, International Journal of Engineering, Science and Technology 2(3).

Stockwell, R. G. (2007). A basis for efficient representation of the S-transform, Digital Signal Processing 17(1), pp. 371-393.

Uyar, M. ; Yildirim, S. ; Gencoglu, M. T. (2004). An expert system based on S-transform and neural network for automatic classification of power quality disturbances, Expert Systems with Applications 36, pp. 5962-5975.

Vega, G. V. ; Duarte G. C. ; Ordóñez P. G. (2009). Automatic Power Quality Disturbances Detection and Classification Based on Discrete Wavelet Transform and Support Vector Machines, Proceedings of the 20th International Conference and Exhibition Electicity Distribution. 
Vetrivel, A. M. ; Malmurugan, N. ; Jovitha, J. (2009). A Novel Method of Power Quality Disturbances Measures Using Discrete Orthogonal S Transform (DOST) with Wavelet Support Vector Machine (WSVM) Classifier, International Journal of Electrical and Power Engineering 3(1), pp. 59-68.

Yong, Z; Hao-Zhong C.; Yi-Feng, D.; Gan-Yun, L.; Yi-Bin, S. (2005). S-Transform-based classification of power quality disturbance signals by support vector machines, Proceedins of the CSEE, pp. 51-56.

Zhu, T. X. ; Tso, S. K. ; Lo, K. L. (2004). Wavelet-Based Fuzzy Reasoning Approach to PowerQuality Disturbance Recognition, IEEE Transaction on Power Delivery 19(4), pp. 1928-1935. 


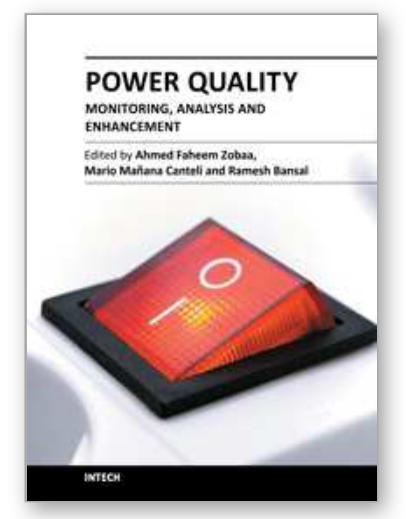

\author{
Power Quality â€“Â Monitoring, Analysis and Enhancement \\ Edited by Dr. Ahmed Zobaa
}

ISBN 978-953-307-330-9

Hard cover, 364 pages

Publisher InTech

Published online 22, September, 2011

Published in print edition September, 2011

This book on power quality written by experts from industries and academics from various counties will be of great benefit to professionals, engineers and researchers. This book covers various aspects of power quality monitoring, analysis and power quality enhancement in transmission and distribution systems. Some of the key features of books are as follows: Wavelet and PCA to Power Quality Disturbance Classification applying a RBF Network; Power Quality Monitoring in a System with Distributed and Renewable Energy Sources; Signal Processing Application of Power Quality Monitoring; Pre-processing Tools and Intelligent Techniques for Power Quality Analysis; Single-Point Methods for Location of Distortion, Unbalance, Voltage Fluctuation and Dips Sources in a Power System; S-transform Based Novel Indices for Power Quality Disturbances; Load Balancing in a Three-Phase Network by Reactive Power Compensation; Compensation of Reactive Power and Sag Voltage using Superconducting Magnetic Energy Storage; Optimal Location and Control of Flexible Three Phase Shunt FACTS to Enhance Power Quality in Unbalanced Electrical Network; Performance of Modification of a Three Phase Dynamic Voltage Restorer (DVR) for Voltage Quality Improvement in Distribution System; Voltage Sag Mitigation by Network Reconfiguration; Intelligent Techniques for Power Quality Enhancement in Distribution Systems.

\title{
How to reference
}

In order to correctly reference this scholarly work, feel free to copy and paste the following:

Gabriel Găşpăresc (2011). Methodes of Power Quality Analysis, Power Quality â€“Â Monitoring, Analysis and Enhancement, Dr. Ahmed Zobaa (Ed.), ISBN: 978-953-307-330-9, InTech, Available from: http://www.intechopen.com/books/power-quality-monitoring-analysis-and-enhancement/methodes-of-powerquality-analysis

\section{INTECH}

open science | open minds

\author{
InTech Europe \\ University Campus STeP Ri \\ Slavka Krautzeka 83/A \\ 51000 Rijeka, Croatia \\ Phone: +385 (51) 770447 \\ Fax: +385 (51) 686166 \\ www.intechopen.com
}

\author{
InTech China \\ Unit 405, Office Block, Hotel Equatorial Shanghai \\ No.65, Yan An Road (West), Shanghai, 200040, China \\ 中国上海市延安西路65号上海国际贵都大饭店办公楼405单元 \\ Phone: +86-21-62489820 \\ Fax: +86-21-62489821
}


(C) 2011 The Author(s). Licensee IntechOpen. This chapter is distributed under the terms of the Creative Commons Attribution-NonCommercialShareAlike-3.0 License, which permits use, distribution and reproduction for non-commercial purposes, provided the original is properly cited and derivative works building on this content are distributed under the same license. 